\title{
Intraosseous fluid resuscitation causes systemic fat emboli in a porcine hemorrhagic shock model
}

\author{
Steinar Kristiansen 1,2,3* ${ }^{\mathbb{D}}$, Benjamin Storm ${ }^{2,3,4}$, Dalia Dahle ${ }^{5}$, Terje Domaas Josefsen ${ }^{5}$, Knut Dybwik ${ }^{2,6}$, \\ Bent Aksel Nilsen² and Erik Waage-Nielsen 2,3,4,6,7
}

\begin{abstract}
Background: Intraosseous cannulation can be life-saving when intravenous access cannot be readily achieved. However, it has been shown that the procedure may cause fat emboli to the lungs and brain. Fat embolization may cause serious respiratory failure and fat embolism syndrome. We investigated whether intraosseous fluid resuscitation in pigs in hemorrhagic shock caused pulmonary or systemic embolization to the heart, brain, or kidneys and if this was enhanced by open chest conditions.

Methods: We induced hemorrhagic shock in anesthetized pigs followed by fluid-resuscitation through bilaterally placed tibial (hind leg) intraosseous cannulas. The fluid-resuscitation was limited to intraosseous or i.v. fluid therapy, and did not involve cardiopulmonary resuscitation or other interventions. A subgroup underwent median sternotomy with pericardiectomy and pleurotomy before hemorrhagic shock was induced. We used invasive hemodynamic and respiratory monitoring including Swan Ganz pulmonary artery catheter and transesophageal echocardiography and obtained biopsies from the lungs, heart, brain, and left kidney postmortem.
\end{abstract}

Results: All pigs exposed to intraosseous infusion had pulmonary fat emboli in postmortem biopsies. Additionally, seven of twenty-one pigs had coronary fat emboli. None of the pigs with open chest had fat emboli in postmortem lung, heart, or kidney biopsies. During intraosseous fluid-resuscitation, three pigs developed significant ST-elevations on ECG; all of these animals had coronary fat emboli on postmortem biopsies.

Conclusions: Systemic fat embolism occurred in the form of coronary fat emboli in a third of the animals who underwent intraosseous fluid resuscitation. Open chest conditions did not increase the incidence of systemic fat embolization.

Keywords: Fat embolism, Fat embolism syndrome, Systemic embolization, Intraosseous cannulation, Coronary fat embolism, Open chest conditions

\section{Background}

The establishment of intraosseous access can be a lifesaving procedure in critically ill patients when venous access cannot be readily achieved by other means $[1,2]$.

*Correspondence: steinarkristiansen@gmail.com

1 Surgery and Intensive Care Unit, University Hospital of Northern Norway, Tromsø, Norway

Full list of author information is available at the end of the article
In critically ill patients, intraosseous access is faster than central venous access [3], and faster [4], or as fast as [5], peripheral intravenous access. Although the procedure is considered to be safe, reported complication rates vary considerably from under $1 \%$ [1], to over $12 \%[2,6]$.

Intraosseous administration of fluids causes fat embolization to the lungs in both clinical case studies and animal studies [3, 7-13]. Systemic fat embolization, original author(s) and the source, provide a link to the Creative Commons licence, and indicate if changes were made. The images or other third party material in this article are included in the article's Creative Commons licence, unless indicated otherwise in a credit line to the material. If material is not included in the article's Creative Commons licence and your intended use is not permitted by statutory regulation or exceeds the permitted use, you will need to obtain permission directly from the copyright holder. To view a copy of this licence, visit http://creativecommons.org/licenses/by/4.0/. The Creative Commons Public Domain Dedication waiver (http://creativeco mmons.org/publicdomain/zero/1.0/) applies to the data made available in this article, unless otherwise stated in a credit line to the data. 
however, has only been seen after trauma or orthopedic surgery [14-16], and it may occur in the absence of an intracardiac shunt [17-20]. To our knowledge, only one case report has described systemic fat embolization after intraosseous cannulation [13], and the phenomenon has not been previously studied in animals.

It has been proposed that open chest, e.g. after emergency thoracotomy [21], may increase the occurrence of systemic air embolization [22]. We, therefore, hypothesized that intraosseous fluid resuscitation would generate both pulmonary and systemic fat emboli, and that open chest would increase systemic embolization.

Thus, our study aimed to examine whether intraosseous fluid resuscitation caused systemic fat embolization, and how this was influenced by open chest conditions. The fat emboli were sought for in postmortem biopsies of the lungs, heart, brain, and left kidney (Table 1).

\section{Methods}

\section{Aim, design, and setting}

In this two-center, non-randomized experimental study, we studied whether intraosseous infusion therapy causes systemic fat embolization in a porcine model for hemorrhagic shock and intraosseous fluid resuscitation. The study design is summarized in Fig. 1.

\section{Experimental animals}

The Norwegian Animal Research Authority approved the study (FOTS ID 19803), and we performed the experiments under the Norwegian Laboratory Animal Regulations and the EU directive 2010/63/EU.

We allocated Norwegian landrace pigs from two farms to undergo intraosseous crystalloid fluid resuscitation following induced hemorrhagic shock, either with midline sternotomy, open pleura, and pericardium (open chest) or closed chest.

Additionally, two animals served as sham, undergoing only standard instrumentation and anesthesia. One animal with patent foramen ovale and one animal with perioperative cardiac arrest were excluded.

\section{Instrumentation, anesthesia, and monitoring}

Anesthesia, instrumentation, and euthanasia were as previously described by Storm et al. [22], elaborated in
Additional file 1. Additionally, a Secalon-T Emergency Catheter MeritMedical, USA) was placed in the left femoral artery.

\section{Exsanguination, intraosseous infusion, and data collection} The intraosseous cannula was inserted in the tibial tuberosity bilaterally (hind legs) using the Arrow EZ-IO intraosseous vascular access system (Teleflex, USA). Cannulation of the marrow cavity was confirmed by loss of resistance on the needle upon entry into the marrow cavity, gentle aspiration of bone marrow, free fluid flow into the bone by injection of $10 \mathrm{ml}$ saline, and detectable fluid bolus in the right ventricular outlet tract by transesophageal echocardiography. After induction and instrumentation, the pigs were exsanguinated through the catheter in the left femoral artery at a rate of $50 \mathrm{ml} / \mathrm{min}$, until a mean arterial pressure (MAP) of $30 \mathrm{mmHg}$ was reached and an arterial blood sample was obtained. After exsanguination, all pigs were resuscitated with an infusion of Lactated Ringers Solution pressurized to $300 \mathrm{mmHg}$ at a rate of approximately $100 \mathrm{ml} / \mathrm{min}$ through both intraosseous cannulas until the MAP was $65 \mathrm{mmHg}$. Infusions were maintained by repeated use of $20 \mathrm{ml}$ syringes connected to pressurized Lactated Ringers Solution. Sham and control animals did not receive intraosseous Lactated Ringers infusion. This method of resuscitation was chosen because it is applied in some emergency clinical settings.

Pigs allocated to the control group underwent sternotomy and were exsanguinated as described above, but fluid resuscitation was administered through intravenous catheters inserted bilaterally in large ear veins.

Pigs allocated to the sham group were not exsanguinated or fluid resuscitated. We euthanized the animals 300 min after the start of the intraosseous infusion by central venous injection of potassium chloride.

We used continuous M-mode and intermittent 2D transesophageal echocardiography (TEE) to verify intraosseous infusion and to detect the systemic passage of emboli by obtaining an echocardiographic window of both the pulmonary artery and the left ventricular outlet tract (LVOT) as described by Storm et al. [22]. We registered elapsed time and eventual systemic passage of emboli (Fig. 2).

Table 1 Postmortem histopathological examination for fat in selected organs

\begin{tabular}{lllll}
\hline Organ & Open chest $(\mathbf{n}=\mathbf{7})$ & Closed chest $(\mathbf{n}=\mathbf{1 4})$ & Sham $(\mathbf{n}=\mathbf{2})$ & Control $(\mathbf{n}=\mathbf{3})$ \\
\hline Lung & $7(100 \%)$ & $14(100 \%)$ & $0(0 \%)$ & $3(100 \%)$ \\
Heart & $0(0 \%)$ & $7(50 \%)$ & $0(0 \%)$ & $0(0 \%)$ \\
Brain & $0(0 \%)$ & $0(0 \%)$ & $0(0 \%)$ & $0(0 \%)$ \\
Kidney & $0(0 \%)$ & $0(0 \%)$ & $0(0 \%)$ & $0(0 \%)$ \\
\hline
\end{tabular}




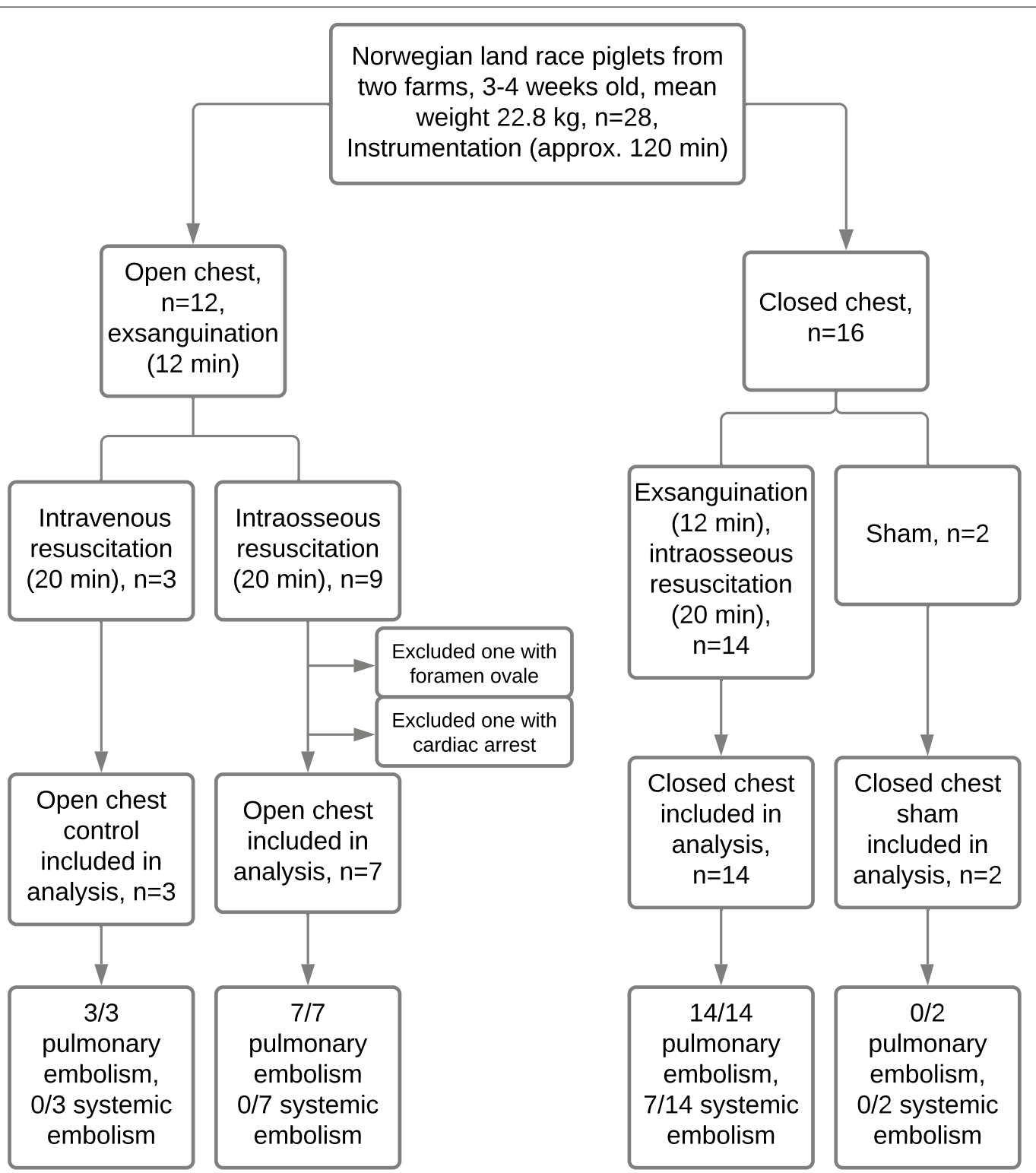

Fig. 1 Inclusion of animals. We allocated 28 pigs to receive intraosseous infusion after induced hemorrhagic shock with either open or closed chest or to serve as sham animals. Open chest animals underwent midline sternotomy

Postmortem, we examined the heart, lungs, left kidney, cerebrum, cerebellum, and the medulla oblongata and obtained biopsies. We screened for intracardiac shunt by echocardiography and postmortem we examined the heart for septal defects such as patent foramen ovale.

\section{Histopathological analyses}

Tissue samples of brain, lung, heart and kidney size $1 \times 1 \times 0.3 \mathrm{~cm}$ were frozen in the OCT compound on dry ice. Sections $8 \mu \mathrm{m}$ thick were cut at $-20{ }^{\circ} \mathrm{C}$ by use of a cryostat (Cryostar NX50, Thermo Scientific, USA).
Three to five serial sections were mounted on poly-Llysine coated slides and air-dried before staining. The sections were fixed with $4 \%$ neutral buffered formalin for 20 min., rinsed in tap water, following by few dips in $60 \%$ isopropanol and incubation in $0.5 \%$ Oil Red O working solution (30 mL 0.5\% Oil Red O (Sigma-Aldrich, St Louis, $\mathrm{MO})$ stock solution diluted with $20 \mathrm{~mL} 1 \%$ dextrin aqueous solution) for $20 \mathrm{~min}$. After incubation samples were shortly rinsed in 60\% isopropanol and counterstained with Gill III modified Hematoxylin solution (Merck KGaA, Darmstadt, Germany) for $15 \mathrm{~s}$, rinsed $3 \times 30 \mathrm{~s}$ with distilled water, blued, and mounted with glycerin 


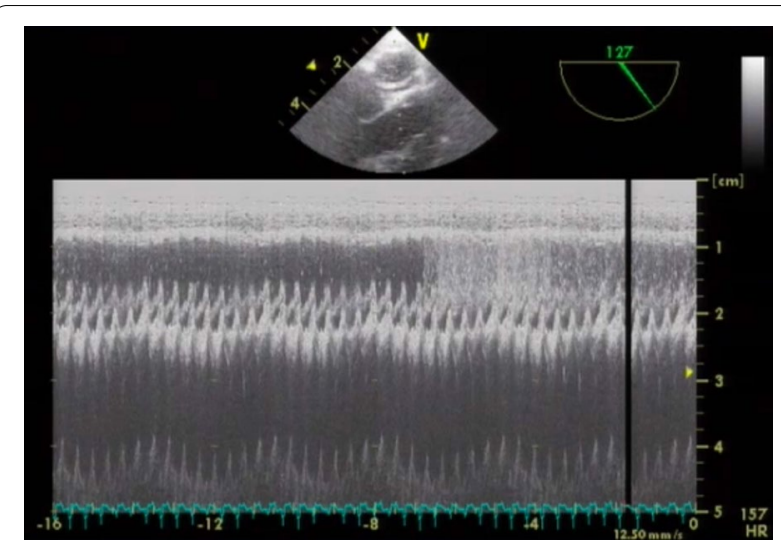

Fig. 2 Transesophageal M-mode echocardiography through the pulmonary artery and the left ventricular outlet tract. Transesophageal M-mode echocardiography (TEE) visualizing the pulmonary artery (above) and the left ventricular outlet tract (below) during intraosseous fluid infusion. We used continuous TEE to help confirm intraosseous placement and to monitor for intracardiac shunt. Horizontal sweep rate was set to $12.50 \mathrm{~mm} / \mathrm{s}$

jelly. Oil Red O stained images were captured by using Olympus SC180 digital camera (Olympus Europa GmbH, Hamburg, Germany) installed on Olympus BX51 light microscope.

The images were processed by using Olympus cellSens Entry software Soft Imaging System GmbH, Munster, Germany). The staining methods are described in Bancroft's Theory and Practice of Histological Techniques [23].

\section{Power calculation}

We expected to find systemic fat emboli in $80 \%$ of the animals with an open chest, and $10 \%$ of the animals with a closed chest, based on previous experience with similar animal models using intravenously injected air [22]. An online sample calculator (https://clincalc.com/stats/ samplesize.aspx) with a 2:1 enrolment ratio, alpha of $5 \%$, and power of $80 \%$, yielded a group-size of 14 with 7 pigs in each group allocated to either open or closed chest.

\section{Statistics}

We used Prism 9 for Mac (Graphpad Software, San Diego, California USA) for statistical calculations and used restricted maximum likelihood mixed model (REML) analysis where statistical comparison was relevant, after testing for normality. We considered a $p<0.05$ significant.

\section{Results}

Detection of systemic and pulmonary fat emboli

By continuous TEE we observed hyperechogenic material consistent with ongoing fluid infusion in the pulmonary artery following intraosseous flush and infusion. Infusion fluid or emboli were not detected in the LVOT, except in the one animal with patent foramen ovale which was excluded.

We found widespread pulmonary fat emboli in all pigs except sham animals in postmortem biopsies. In seven of 21 pigs in the intraosseous group, we found fat emboli in coronary arteries of the left ventricle. All pigs with coronary fat emboli were from the closed chest group. We did not find fat emboli in renal biopsies or biopsies from the dorsal and ventral cerebrum and cerebellum.

\section{Clinical manifestations of fat embolization Pulmonary manifestations}

Only pigs with open chest developed a mild oxygenation failure with $\mathrm{PaO} 2$ :FiO2 ratio at $301 \mathrm{mmHg}$, compared to pigs with closed chest, which had normal oxygenation, with an average $\mathrm{PaO} 2: \mathrm{FiO} 2$ ratio of 363 $(p=0.04)$.

\section{Cardiovascular manifestations}

5-lead ECG revealed significant ST-elevation (>1 mm ST-elevation in minimum two standard leads lasting $>15 \mathrm{~min}$ ) following intraosseous resuscitation in three animals in the closed group, who all were found to have cardiac fat embolization post-mortem. There were no further signs of cardiovascular deterioration.

Post-mortem macroscopic examination of the heart and lungs did not reveal marked pathology.

\section{Time to death after intraosseous infusion}

All pigs survived throughout the $300 \mathrm{~min}$ experiments without interventions other than maintenance fluid therapy.

\section{Discussion}

In a porcine model, we have shown that intraosseous fluid resuscitation causes systemic fat embolization in addition to pulmonary emboli. Our findings suggest that intraosseous cannulation and/or infusion may cause widespread pulmonary fat emboli, supporting current literature $[8,9]$.

Three control animals also developed pulmonary fat emboli, which we believe came from the median sternotomy, a procedure known to cause fat embolization [24-26].

Intraosseous fluid resuscitation caused fat emboli to be dislodged in the coronary vessels of the left ventricle 
in animals with closed chests. To our knowledge, systemic fat embolization confirmed by biopsies following intraosseous cannulation and/or infusion has not been described in an animal model. Systemic fat embolization following intraosseous infusion has been documented in one single clinical case [13]. We found cardiac fat emboli only in pigs with closed chest. This may suggest, with the limitation of few pigs in the series, that an open chest does not reduce the threshold for when fat reaches the systemic circulation through the lungs, as is the case concerning air emboli [22].

The pigs did not develop clinical fat embolism syndrome for the duration of the experiments, a finding consistent with previous literature [9]. We observed significant ST-elevations in three animals who were found to have coronary fat emboli. The lack of major clinical deterioration may be explained by the fact that fat embolism syndrome usually occurs $24-72 \mathrm{~h}$ after the embolic event [16, 27-29].

We analyzed several anatomical separate slices of each animal's brain and kidneys but did not find convincing evidence of intravascular fat emboli. The fact that systemic fat emboli were only found in coronary vessels may be random, and the lack of emboli in the brain and renal biopsies does not exclude the possibility that embolization to these tissues occurred. Moreover, preparation of brain tissue for oilred $\mathrm{O}$ staining proved challenging, which may have caused us to miss cerebral fat emboli. More numerous biopsies and improved technique for preparing brain tissue would increase the sensitivity in discovering further systemic embolization. Cerebral magnetic resonance imaging (MRI) with susceptibility weighted imaging (SWI) would to a high degree of certainty reveal fat embolization to the brain, as has been shown clinically [15, 30-32] (Fig. 3).

Diagnosing fat embolism syndrome in patients can also prove difficult. Biopsies are only obtained from the minority of patients who die, and if they are obtained, biopsy material is not routinely stained with oilred $\mathrm{O}$ to identify fat emboli. The more common symptoms from fat embolism syndrome such as respiratory failure and neurological symptoms have low sensitivity, with the typical petechial rash having higher spesifisity but occurring in only $20-50 \%$ of patients [33]. As cerebral fat emboli cause petechial hemorrhages, magnetic resonance imaging (MRI) with susceptibility weighted imaging (SWI) is perhaps the most valuable diagnostic tool in living patients [13, 32, 34]. However, our experience is that magnetic resonance imaging with SWI weighted imaging is not routinely performed, and further, that MRI is obtained only rarely if fat embolism syndrome is suspected (Fig. 4).

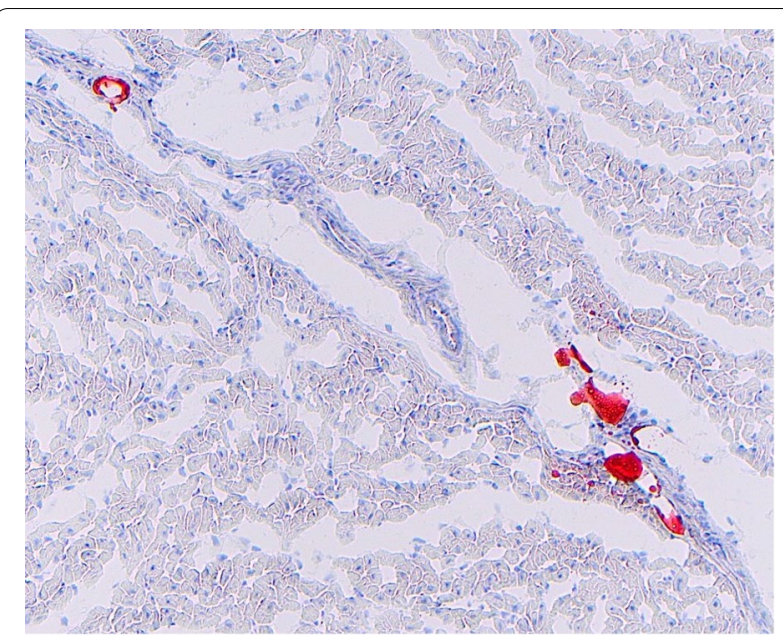

Fig. 3 Frozen myocardial tissue stained Oil RedO and counterstained with Hematoxylin Gill III. Left ventricle of the heart, Oilred O stain on frozen tissue conterstained with Hematoxylin Gill III showing several intravascular fat emboli (100x total magnification)

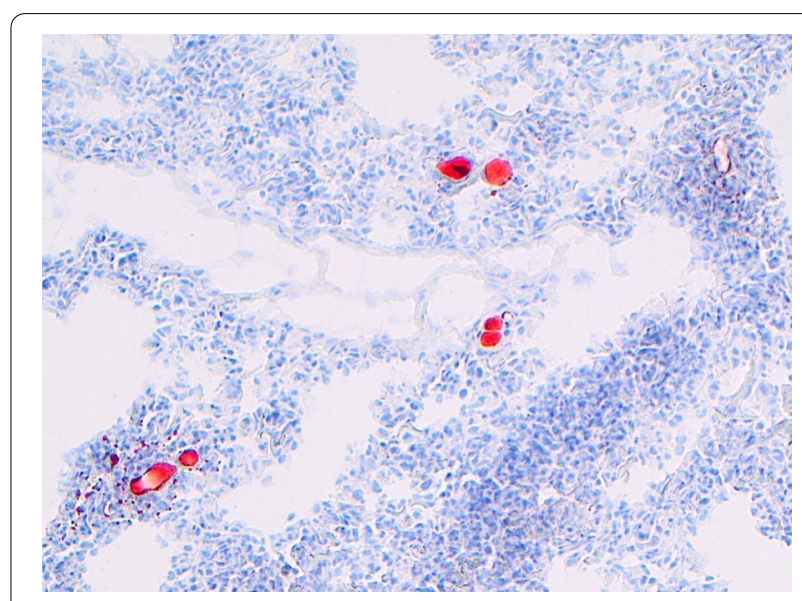

Fig. 4 Frozen pulmonary tissue stained Oil RedO and counterstained with Hematoxylin Gill III. Posterior lobe of left lung, Oilred O staining counterstained with Hematoxylin Gill III on frozen tissue showing multiple intravascular fat emboli ( $100 \times$ total magnification)

\section{Systemic embolization}

Systemic passage of emboli occurred in several animals, in all cases in the form of coronary embolization, and only in animals with closed chest. Systemic passage - or shunting - occurred in the closed chest group as evident by the presence of coronary fat emboli. None of the included animals had an intracardiac shunt. Systemic passage of emboli in the absence of intracardiac shunt has been shown in humans and animals [20,35-38]. Venous emboli can theoretically enter the systemic circulation through at least three sites; the pulmonary capillary network, 
an intracardiac shunt - for example an open foramen ovale-or through extra-alveolar shunt-vessels, more commonly referred to as anatomical shunts [35, 39]. It has been proposed that intravascular fat emboli may be "squeezed through" the pulmonary capillary network, i.e. that small pulmonary fat emboli may migrate through the pulmonary capillary network and cause systemic embolization [20].

In addition, extra-alveolar shunts exist in healthy humans $[35,39,40]$, likely contributing to systemic embolization. The extent of shunting through these vessels is probably dynamic, as the shunting appears to increase with hypoxia, posture change, and exercise $[35,39,40]$.

In our experiments, we hypothesized that an open chest would increase systemic fat embolization. We believed that an open chest would cause reduced transmural lung pressure, allowing over-expansion of the lungs. This, in conjunction with mechanical ventilation, has been proposed to facilitate the recruitment of extra-alveolar shunt vessels, thus opening up dynamic passages available for systemic shunting for air emboli $[22,41]$. Fat emboli likely do not share the gravitational, thrombogenic, or physical properties of air emboli, and are probably influenced by the mentioned factors in other ways.

\section{Clinical relevance}

We have demonstrated that intraosseous infusion causes pulmonary and potentially coronary fat embolization, and that systemic embolization did not occur in animals with open chest. Intraosseous infusion is used when intravenous access is difficult, as is often the case in patients with serious hypovolemia or hypotension. In critically ill patients, delayed fluid or drug administration may be fatal. Intraosseous access may be warranted in time-critical situations, despite a high probability of pulmonary emboli and a risk of coronary and cerebral embolization, as these emboli may commonly be subclinical. Thus, open chest situations, as with thoracic trauma and emergency thoracotomy, do not by itself seem to contraindicate intraosseous cannulation.

\section{Limitations}

Our study has potential limitations. A subgroup of pigs was exposed to both sternotomy and intraosseous infusion, and both interventions are known to cause fat embolization, possibly placing these pigs at a higher risk of systemic passage of fat emboli. Despite this, no coronary fat emboli were observed in pigs with open chest. Thus, it is reasonable to conclude that the intraosseous infusion, and not the sternotomy, was the most significant source of fat emboli in both pigs with open and closed chest. We conducted the experiments at two laboratories, possibly introducing a bias in our findings. However, as all experiments were conducted by the same researchers using identical protocols, medications, and equipment is is not likely that this has affected our findings to any extent. Further, the animals were of the same race and bred from the same national insemination stock and supplier. Echocardiography was performed by two different researchers, and neither detected passage of systemic fat emboli, even in cases where fat emboli were found in postmortem left ventricle biopsies, suggesting that the TEE had a low sensitivity for the detection of the systemic passage of fat emboli.

The distribution of systemic fat emboli in the tissues is unpredictable, and despite acquiring several tissue biopsies postmortem, we sampled only a fraction of the organs, and organ embolization may indeed have occurred without us detecting them in the sampled tissue. Finally, it is established that clinical fat embolism syndrome usually does not manifest itself until 24-48 h after fat embolization has occurred [16, 29, 42]; our observational period was limited to $300 \mathrm{~min}$. Thus, we cannot exclude the possibility that the fat emboli would later have caused fat embolism syndrome.

\section{Conclusions}

Pulmonary fat emboli were ubiquitous during intraosseous infusion and systemic passage of fat emboli frequently occurred, but did not cause major respiratory or cardiovascular deterioration. Open chest conditions did not increase the risk of systemic passage of fat emboli.

\section{Supplementary Information}

The online version contains supplementary material available at https://doi. org/10.1186/s13049-021-00986-z.

Additional file 1. Methods and materials.

Acknowledgements

Not applicable.

Author contribution

SK is the corresponding author, did background literature research, applied for funding and other obligatory applications for animal research, designed, planned, and conducted the experiments, organized, and analyzed all data obtained during and after the experiments. BSS contributed to the practical conduction of the animal experiments including basic infrastructure, data sampling, and monitoring equipment, and practical expertise during animal experiments and revision of the manuscript. DD and TJ contributed to obtaining accurate biopsy material post-mortem, the preparation, handling, and analysis of this material as described in Methods under histopathological 
analyses. KD contributed to the practical conduction of the animal experiments including providing basic infrastructure. BAN contributed to the practical conduction of the animal experiments, including providing basic infrastructure, animal pre-handling, and transportation. EWN has contributed to developing the model and research hypotheses, background literature research, applications, participated with practical expertise in the planning and practical conduction of animal experiments, and co-authorship during the publication process. All authors contributed to the revision of this manuscript and approved before it was submitted. All authors read and approved the final manuscript.

\section{Funding}

The study has received funding from Helse Nord, Odd Berg Gruppen, and the Blix Family Fund, all in Norway.

\section{Availability of data and materials}

The datasets from the experiments are available from the corresponding author on request.

\section{Declarations}

\section{Ethics approval and consent to participate}

The Norwegian Animal Research Authority approved the study, and we performed the experiments under the Norwegian Laboratory Animal Regulations and the EU directive 2010/63/EU.

\section{Consent for publication}

Not applicable.

\section{Competing interests}

The authors declare no competing interests.

\section{Author details}

'Surgery and Intensive Care Unit, University Hospital of Northern Norway, Tromsø, Norway. ${ }^{2}$ Department of Surgery, Nordland Hospital Trust, Bodø, Norway. ${ }^{3}$ Department of Clinical Medicine, Faculty of Health Sciences, Arctic University of Norway, Tromsø, Norway. ${ }^{4}$ Research Laboratory, Nordland Hospital Trust, Bodø, Norway. ${ }^{5}$ Faculty of Biosciences and Aquaculture, Nord University, Bodø, Norway. ${ }^{6}$ Faculty of Nursing and Health Sciences, Nord University, Bodø, Norway. ${ }^{7}$ Department of Immunology, Oslo University Hospital, University of Oslo, Oslo, Norway.

Received: 20 September 2021 Accepted: 9 November 2021

Published online: 20 December 2021

\section{References}

1. Petitpas F, Guenezan J, Vendeuvre T, Scepi M, Oriot D, Mimoz O. Use of intra-osseous access in adults: a systematic review. Crit Care. 2016;20:102. https://doi.org/10.1186/s13054-016-1277-6.

2. Anson JA. Vascular access in resuscitation is there a role for the intraosseous route? Anesthesiology. 2014;120:1015-31. https://doi.org/10.1097/ ALN.0000000000000140.

3. Leidel BA, Kirchhoff C, Bogner V, Braunstein V, Biberthaler P, Kanz K-G. Resuscitation comparison of intraosseous versus central venous vascular access in adults under resuscitation in the emergency department with inaccessible peripheral veins. Resuscitation. 2011;83:40-5.

4. Reades R, Studnek JR, Vandeventer S, Garrett J. Intraosseous versus intravenous vascular access during out-of-hospital cardiac arrest: a randomized controlled trial. Ann Emerg Med. 2011;58:509-16. https://doi.org/ 10.1016/J.ANNEMERGMED.2011.07.020.

5. Clemency B, Tanaka K, May P, Innes J, Zagroba S, Blaszak J, et al. Intravenous vs. intraosseous access and return of spontaneous circulation during out of hospital cardiac arrest. Am J Emerg Med. 2017;35:222-6. https://doi.org/10.1016/J.AJEM.2016.10.052.

6. Hallas P, Brabrand M, Folkestad L. Complication with intraosseous access: scandinavian users' experience. West J Emerg Med. 2013;14:440-3.

7. Rubal BJ, Meyers BL, Kramer SA, Hanson MA, Andrews JM, DeLorenzo RA. Fat intravasation from intraosseous flush and infusion procedures.
Prehospital Emerg Care. 2015;19:376-90. https://doi.org/10.3109/10903 127.2014.980475.

8. Hasan MY, Kissoon N, Khan TM, Saldajeno V, Goldstein J, Murphy SP. Intraosseous infusion and pulmonary fat embolism. Pediatr Crit Care Med. 2001;2:133-8. https://doi.org/10.1097/00130478-200104000-00007.

9. Orlowski JP, Julius CJ, Petras RE, Porembka DT, Gallagher JM. The safety of intraosseous infusions: risks of fat and bone marrow emboli to the lungs. Ann Emerg Med. 1989;18:1062-7. https://doi.org/10.1016/S01960644(89)80932-1.

10. Fiallos M, Abdelmoneim T, Kissoon N, Johnson L, Murphy S, Masood S, et al. Incidence of fat and bone marrow embolism with the use of intraosseous infusion during cardio-pulmonary resuscitation. † 264. Pediatr Res. 1996;39:46-46. https://doi.org/10.1203/00006450-199604001-00283.

11. Rubal BJ, Hanson MA. Fat intravasation from intraosseous infusions. Circulation. 2012.

12. Fiallos M, Kissoon N, Abdelmoneim T, Johnson L, Murphy S, Lu L, et al. Fat embolism with the use of intraosseous infusion during cardiopulmonary resuscitation. Am J Med Sci. 1997;314:73-9.

13. May F, Hodel J, Mekontso Dessap A, Razazi K. Cerebral fat embolism after intraosseous infusion. Intensive Care Med. 2019;45:257-8. https://doi.org/ 10.1007/s00134-018-5431-2.

14. Heisel C, Mau H, Borchers T, Müller J, Breusch SJ. Fettembolie bei der hüftendoprothesen-implantation. Zementfrei gegen zementiert - Ein quantitativer In vivo-Vergleich im Tiermodell. Orthopade. 2003;32:247-52. https://doi.org/10.1007/s00132-002-0394-x.

15. Shaikh N, Parchani A, Bhat V, Kattren MA. Fat embolism syndrome: clinical and imaging considerations: case report and review of literature. Indian J Crit Care Med. 2008;12:32-6. https://doi.org/10.4103/0972-5229.40948.

16. Kwiatt M, Seamon M. Fat embolism syndrome. Int J Crit IIIn Inj Sci. 2013;3:64. https://doi.org/10.4103/2229-5151.109426.

17. Simon AD, Ulmer JL, Strottmann JM. American journal of neuroradiology. Am J Neuroradiol. 2003;9:212-3.

18. Eriksson EA, Schultz SE, Cohle SD, Post KW. Cerebral fat embolism without intracardiac shunt: a novel presentation. J Emerg Trauma Shock. 2011;4:309-12.

19. Kristiansen $S$, Madsen MR, Steen R, Nielsen EW. A young trauma patient with five fractures and multi-organ failure. Tidsskr Den Nor legeforening. 2018. https://doi.org/10.4045/tidsskr.17.0898.

20. Nikolić S, Živković V, Babić D, Djonić D, Djurić M. Systemic fat embolism and the patent foramen ovale: a prospective autopsy study. Injury. 2012;43:608-12. https://doi.org/10.1016/j.injury.2010.08.027.

21. Dayama A, Sugano D, Spielman D, Stone ME, Kaban J, Mahmoud A, et al. Basic data underlying clinical decision-making and outcomes in emergency department thoracotomy: tabular review. ANZ J Surg. 2016;86:216. https://doi.org/10.1111/ans.13227.

22. Storm BS, Halvorsen PS, Skulstad H, Dybwik K, Schjalm C, Christiansen $D$, et al. Open chest and pericardium facilitate transpulmonary passage of venous air emboli. Acta Anaesthesiol Scand. 2021. https://doi.org/10. 1111/aas.13796.

23. Bancroft JD, Suvarna K, Layton C. Bancrofts theory and practice of histological techniques. 7th ed. London: Churchill Livingstone; 2013.

24. Eyjolfsson A. Lipid micro emboli in cardiac surgery. 2011. https://lup.lub. lu.se/search/ws/files/3568836/2223982.pdf. Accessed 21 Apr 2021.

25. Ariff AM. Post-operative fat embolism syndrome: A case report and review of literature.

26. Brown WR, Moody DM, Challa VR. Cerebral fat embolism from cardiopulmonary bypass. J Neuropathol Exp Neurol. 1999;58:109-19. https://doi. org/10.1097/00005072-199902000-00001.

27. Atlee J. Complications in anesthesia. Elsevier Inc; 2007.

28. Caplan LR. Caplan's stroke: a clinical approach. 4th ed. Elsevier Inc; 2009.

29. Vetrugno L, Bignami E, Deana C, Bassi F, Vargas M, Orsaria M, et al. Cerebral fat embolism after traumatic bone fractures: a structured literature review and analysis of published case reports. Scand J Trauma Resusc Emerg Med. 2021;29:1-9. https://doi.org/10.1186/S13049-021-00861-X.

30. Shaikh N, Mahmood Z, Ghuori SI, Chanda A, Ganaw A, Zeeshan Q, et al. Correlation of clinical parameters with imaging findings to confirm the diagnosis of fat embolism syndrome. Int J Burns Trauma. 2018;8:135-44.

31. May F, Hodel J, Dessap AM, Razazi K. Cerebral fat embolism after intraosseous infusion. Intensive Care Med. 2019;45:257-8. https://doi.org/10. 1007/s00134-018-5431-2. 
32. Giyab O, Balogh B, Bogner P, Gergely O, Tóth A. Microbleeds show a characteristic distribution in cerebral fat embolism. Insights Imaging. 2021;12:42. https://doi.org/10.1186/s13244-021-00988-6.

33. Gupta A, Reilly CS. Fat embolism. Contin Educ Anaesth Crit Care Pain. 2007;7:148-51. https://doi.org/10.1093/BJACEACCP/MKM027.

34. Sethi D, Kajal S, Saxena A. Neuroimaging findings in a case of cerebral fat embolism syndrome with delayed recovery. Indian J Crit Care Med. 2015;19:674-7. https://doi.org/10.4103/0972-5229.169350.

35. Lovering AT, Elliott JE, Beasley KM, Laurie SS. Pulmonary pathways and mechanisms regulating transpulmonary shunting into the general circulation: an update. Injury. 2010;41(Suppl. 2):S16. https://doi.org/10.1016/ S0020-1383(10)70004-8.

36. Byrick RJ, Kay JC, Mazer CD, Wang Z, Mullen JB. Dynamic characteristics of cerebral lipid microemboli: videomicroscopy studies in rats. Anesth Analg. 2003;97:1789-94. https://doi.org/10.1213/01.ANE.0000090010. 11582.25.

37. Byrick RJ, Mullen JB, Mazer CD, Guest CB. Transpulmonary systemic fat embolism: studies in mongrel dogs after cemented arthroplasty. Am J Respir Crit Care Med. 1994;150(5):1416-22. https://doi.org/10.1164/ ajrccm.150.5.7952570.

38. Nijsten MWN, Hamer JPM, Ten Duis HJ, Posma JL. Fat embolism and patent foramen ovale. The Lancet. 1989;333:1271. https://doi.org/10.1016/ S0140-6736(89)92370-2.

39. Eldridge MW, Dempsey JA, Haverkamp HC, Lovering AT, Hokanson JS. Exercise-induced intrapulmonary arteriovenous shunting in healthy humans. J Appl Physiol. 2004;97:797-805. https://doi.org/10.1152/jappl physiol.00137.2004.

40. Lovering AT, Romer LM, Haverkamp HC, Pegelow DF, Hokanson JS, Eldridge MW. Intrapulmonary shunting and pulmonary gas exchange during normoxic and hypoxic exercise in healthy humans. J Appl Physiol. 2008:104:1418-25. https://doi.org/10.1152/japplphysiol.00208.2007.

41. Cortes-Puentes GA, Oeckler RA, Marini JJ. Physiology-guided management of hemodynamics in acute respiratory distress syndrome. Ann Transl Med. 2018;6:353-353. https://doi.org/10.21037/ATM.2018.04.40.

42. DeFroda SF, Klinge SA. Fat embolism syndrome with cerebral fat embolism associated with long-bone fracture. Am J Orthop Belle Mead NJ. 2016:45:515-21.

\section{Publisher's Note}

Springer Nature remains neutral with regard to jurisdictional claims in published maps and institutional affiliations.

- fast, convenient online submission

- thorough peer review by experienced researchers in your field

- rapid publication on acceptance

- support for research data, including large and complex data types

- gold Open Access which fosters wider collaboration and increased citations

- maximum visibility for your research: over 100M website views per year

At BMC, research is always in progress.

Learn more biomedcentral.com/submissions 